\title{
Experimental Study on Sand Inrush Hazard of Water-Sand Two- Phase Flow in Broken Rock Mass
}

\author{
Junce Xu $\mathbb{D}^{1},{ }^{1}$ Hai Pu $\mathbb{D}^{1,2}$ Jiarui Chen $\mathbb{D}^{3},{ }^{3}$ and Ziheng Sha $\mathbb{D}^{1}$ \\ ${ }^{1}$ State Key Laboratory for Geomechanics \& Deep Underground Engineering, China University of Mining \& Technology, Xuzhou, \\ Jiangsu 221116, China \\ ${ }^{2}$ College of Mining Engineering and Geology, Xinjiang Institute of Engineering, Urumqi, Xinjiang 830091, China \\ ${ }^{3}$ Faculty of Architecture and Civil Engineering, Huaiyin Institute of Technology, Huai'an, Jiangsu 223001, China
}

Correspondence should be addressed to Hai Pu; haipu@cumt.edu.cn

Received 7 January 2021; Revised 24 March 2021; Accepted 28 March 2021; Published 7 April 2021

Academic Editor: Chun Zhu

Copyright ( 2021 Junce Xu et al. This is an open access article distributed under the Creative Commons Attribution License, which permits unrestricted use, distribution, and reproduction in any medium, provided the original work is properly cited.

\begin{abstract}
In the western region of China, coal mining activities are prone to induce water and sand inrush disasters, which seriously threaten the safe production of the coal resources. In this paper, an experimental device was designed to simulate the process of water and sand inrush, and then, the control factors of the disasters in the broken rock mass in the goaf were investigated. Also, the seepage fracture channels in the broken rock mass were simplified by using the 3D printing technology, and the effects of fracture aperture and angle on the seepage characteristics of water-sand mixtures were analyzed. The experimental results showed that the porosity and skeleton structure of the broken rock mass were the key factors to control the water and sand inrush disasters. The smaller the initial porosity of the broken rock mass, the weaker its permeability, and the less probable to form a dominant channel for the water and sand inrush disasters. Conversely, the broken rock mass structure with larger size gradation was more likely to form the permeable channels, and the quality of the sand inrush was greater. In addition, it was also found that the angle of the fractures within the broken rock mass affected the seepage characteristics of water-sand mixture, and the permeability showed an exponential relationship with the fracture angle. Meanwhile, as the fracture aperture increased, the fracture angle generated greater influence on the permeability. Finally, we proposed the water and sand inrush prevention and control technology based on the experiment results. The results of this study can provide a reference for the control of water and sand inrush disasters in western China.
\end{abstract}

\section{Introduction}

Abundant coal resources (36\% of coal resources) are found in the western region of China; however, it is prone to have water and sand inrush disasters in the mining process due to the fragile ecological environment in the western region [1-3]. As presented in Figure 1 [4], the broken rock mass (porous skeleton) in the caving zone connects the aquifer and the goaf zone during the mining process, constituting an effective channel for the transport of water-sand mixed fluids $[5,6]$. The sand-water mixed fluid is then transported through the fractures in the broken rock mass and gushed into the working area [7]. Subsequently, it flooded the mining equipment in the working face, causing casualties and equipment damage [8-10]. In addition, water and sand inrush disasters also lead to environmental damage, such as surface collapse, groundwater contamination, and other problems $[11,12]$. Therefore, to explore the factors affecting the process of water and sand inrush has practical engineering significance and economic values.

As for the generation of water and sand inrush disasters, scholars at home and abroad have explored this issue in various aspects $[13,14]$. Based on the engineering case studies, Kesseru proposed and validated a new method to distinguish the occurrence of water and sand inrush by the mine tests and failure experience [15]; Zhang and Hou summarized the four necessary influencing factors for water and sand inrush hazard by analyzing the hydrological and engineering geological conditions of shallow buried coal seam mining [16]; Dash et al. concluded the prerequisites for the 


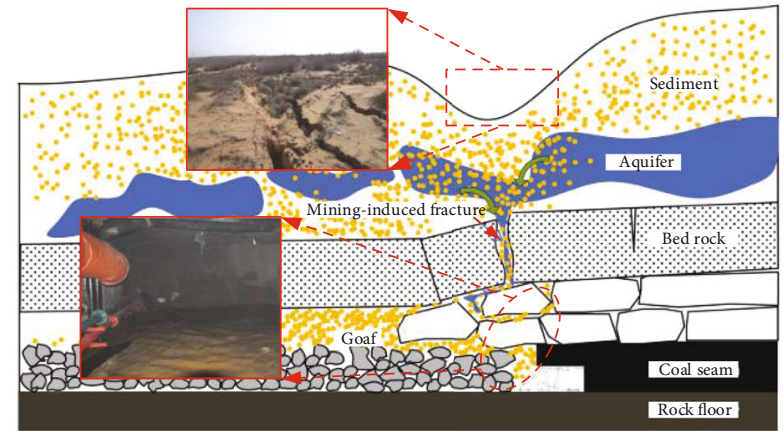

Figure 1: The schematic diagram of the water and sand inrush disasters as well as the images of the disaster on site (after [4]).

occurrence of sudden floods by analyzing coal mines in India [17]; Zhang and Lin put forward a calculation method applicable to the volume flux of quicksand disaster based on the case of Longde coal mine project in China [18]; according to the case study of Xiexin coal mine, Li et al. proposed a water and sand control system for the mining of extrathick coal seams under unconsolidated Cenozoic alluvium [6]. However, these methods are only regularity studies and not why. Besides, based on the numerical simulation method, $\mathrm{Pu}$ et al. combined it with the lattice Boltzmann method (LBM) to explore the effect of fracture openings on the amount of sand inrush [19]; Wang et al. adopted the discrete element method (DEM) to develop a three-dimensional model of the flow-solid two-phase to analyze the watersand transport process during the water and sand inrush [20]; Ma et al. simulated the process of water and sand inrush disaster on engineering scale by computational fluid dynamics (CFD) method and proposed basic measures for disaster prevention and control, that is, surface fracture backfill, grouting reinforcement, dewatering, and depressurization [4]. But these methods all simplify the process of water and sand inrush, which is difficult to correspond with the actual situation. Therefore, some scholars have attempted to study the process and mechanism of the occurrence of water and sand inrush disasters through the experimental methods: Sui et al. discovered that the initial water pressure of the aquifer and the aperture of the sand inrush fractures were the key factors affecting the number of sand emergence from the coal mine workings using indoor experiments [21]; owing to the results of granular rock seepage tests, Zhang et al. conducted a water and sand inrush test and proposed the critical conditions for the occurrence of water and sand inrush disaster [22]; Yang et al. systematically analyzed the fracture evolution characteristics of the overburden rock layers in shallow thick coal seams by the physical simulation, theoretical analysis, and field observation [23]; Chen et al. explored the mechanism of water and sand inrush disasters under different clay content conditions in the loose layer [3]. Indeed, the fractures in the broken rock mass play an important role in controlling the water and sand transport [24-26]. At the same time, the shape of fractures in overlying rocks shows variations influenced by different forms of forces and locations $[7,27]$. However, the relevant studies on the experiments of water and sand inrush were not well studied, especially considering the effect of fissures.
Therefore, in this paper, the tests of water and sand inrush were carried out by self-designed relevant experimental devices. Moreover, the process of water-sand seepage along the fracture channel during mining was simulated for rock mass with different degrees of brokenness. Based on the testing results, the effects of different initial porosity on the seepage of water-sand and the quality of the sand outbursts were analyzed. In addition, the influence of the fracture angle and aperture on the migration characteristics of sand-water mixture was also analyzed in combination with $3 \mathrm{D}$ printing technology. Finally, the research results contribute to further understanding of the water and sand inrush disasters and provide guidance for the prevention of the disasters caused by coal mining.

\section{Laboratory Experiments on Water and Sand Inrush}

2.1. Experimental Materials. As shown in Figure 2, the sand grains used in the test were aeolian sand harvested from Yulin, northern Shaanxi, China. The sampling site of the sand was only $20 \mathrm{~km}$ away from the Longde coal mine. The particle size distribution of the test sand is shown in Figure 3, and its average particle size was $0.25 \mathrm{~mm}$. The aeolian sand density was $1174 \mathrm{~kg} / \mathrm{m}^{3}$, and the natural porosity is about $54 \%$. The mudstone samples selected for this study were also obtained from the Longde coal mine, and the samples were then made into different size particles using a crusher. Next, a sieve was used to classify the samples into five ranges of particle size (see Figure 2), namely, 5.0-8.0 mm (size range 1), $8.0-10.0 \mathrm{~mm}$ (size range 2), 10.0-12.0 $\mathrm{mm}$ (size range 3 ), $12.0-15.0 \mathrm{~mm}$ (size range 4 ), and 15.0-20.0 $\mathrm{mm}$ (size range 5).

\subsection{Design of Test Equipment}

2.2.1. Experimental Device for Water and Sand Inrush. In order to conduct the water and sand inrush experiment, an experimental system was designed, including self-designed seepage test device and MTS816 servo loading device. The schematic and physical diagram of the water-sand mixture seepage test device is presented in Figure 4, which mainly consists of water pressure device, storage device for watersand mixture, broken rock storage device, orifice device for water-sand influx, recording device, pressure sensor, etc. In the tests, the screened broken rock mass was put into the cylindrical chamber, and then, a seepage plate was placed above the broken rock masses. Next, as shown in Figure 4(a), the aeolian sand was placed into a pressurebearing ring. Additionally, an MTS816 servo-controlled testing machine was used to apply load to the seepage experimental device (Figure 4(c)). During the testing, the seepage device was loaded axially by the lower piston (Figure 4(a), 7 ) to compress the granular rock mass under lateral restraint.

Furthermore, an advance verification test was conducted to satisfy Darcy's law for the experimental percolation process. A pump was used to inject $0.5 \mathrm{MPa}$ pressure water flow from the upper part of the apparatus, and the lower part was at standard atmospheric pressure. The test results showed that the pressure gradient of water through the broken rock 

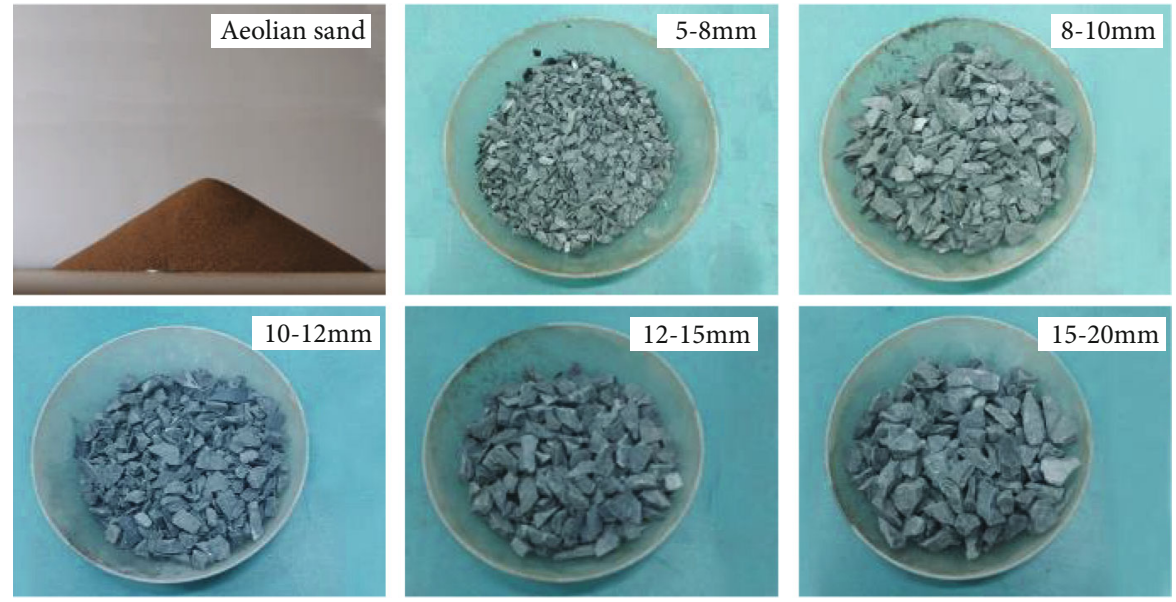

FIGURE 2: Experimental materials.

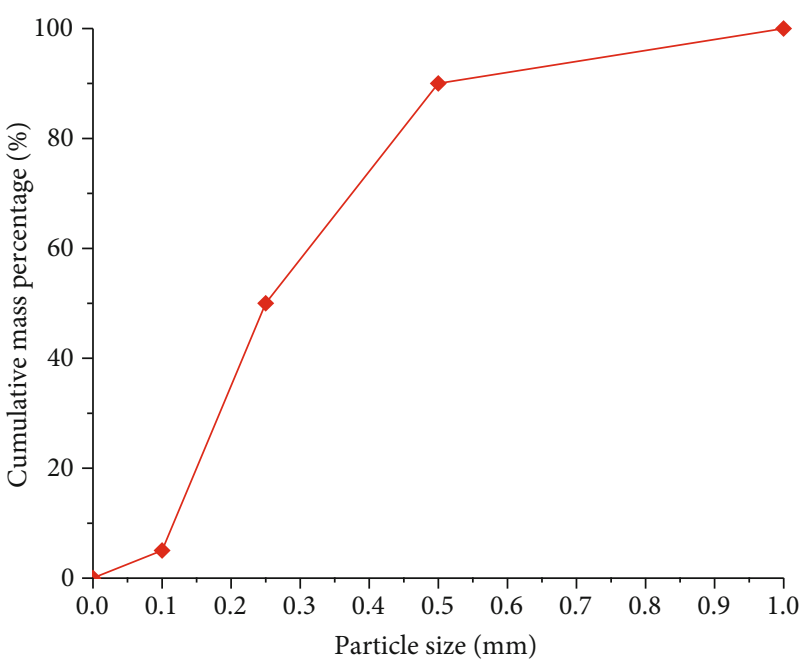

FIGURE 3: Grain size distribution curve of the aeolian sand.

sample was about $5 * 10^{-3} \mathrm{MPa} / \mathrm{mm}$, which is similar to the results of previous studies [22]. Therefore, the seepage in the broken rock samples under the above pressure gradient follows Darcy's law.

Besides, a viscometer was used to measure the apparent viscosity of the water-sand mixture, as shown in Table 1 , which is a power law-type non-Newtonian fluid.

$$
\mu_{\mathrm{a}}=0.246 \times \gamma_{\mathrm{s}}^{-0.8894}, \quad R^{2}=0.995
$$

where $\mu_{\mathrm{a}}$ is surface viscosity and $\gamma_{\mathrm{s}}$ refers to shearing rate.

2.2.2. Fracture Seepage Experimental Device. The geometry of the fracture in the broken rock mass was a significant factor affecting the water and sand inrush $[7,28]$. In order to further analyze the seepage characteristics of water and sand mixture in the fractures, the fracture channel in broken rock mass was simplified. However, rock is a hard and brittle material, and it is difficult to create cracks of specific apertures and angles in the rock in a laboratory setting. As shown in Figure 5, we employed a $3 \mathrm{D}$ printer to produce single fracture samples of different shapes. Each fracture test piece was height $h$ $(100 \mathrm{~mm})$. The fracture aperture $l$ was $2,3,4,5$, or $6 \mathrm{~mm}$; and the fracture angle $\alpha$ was $45^{\circ}, 55^{\circ}, 65^{\circ}, 75^{\circ}$, or $90^{\circ}$. For the five fracture apertures and five angles, 25 test pieces were made. Further, the screw threads were machined at the two ends of each test piece so that they could be easily installed into the test piece sleeve. Moreover, the screw threads were wrapped with thread seal tape to prevent the seepage of water along them.

2.3. Experimental Method. In this test, since a constant axial pressure was applied by the MTS816 system, it was difficult to determine the deformation behavior of the broken rock mass samples with different grain sizes directly. So to determine the deformation of the broken rock mass under the load, the uniaxial creep tests were conducted. From Figure 6, there are obvious differences in the deformation of the samples under the same loading conditions, and the greater the gradation of the fractured rock samples, the greater the degree of deformation. Consequently, according to the deformation law, the samples with specified height can be obtained by loading. The detailed experimental steps are as follows. (It should be noted that for the fracture seepage test, no load needs to be applied.)

Step 1. Put the broken rock samples with different particle size distribution into the cylindrical chamber of the permeation test device (see Figure 4(a), 10).

Step 2. Place a seepage plate and an annular pressure-bearing ring above the broken rock sample; then, put the selected aeolian sand (total $500 \mathrm{~g}$ ) into the pressure-bearing ring. Note that the mass of sand is the same for each sample.

Step 3. Load samples to a specified height of $150 \mathrm{~mm}$ via MTS816.

Step 4. Connect the pump to the water penetration test device and keep the inlet pressure at $0.5 \mathrm{MPa}$. 


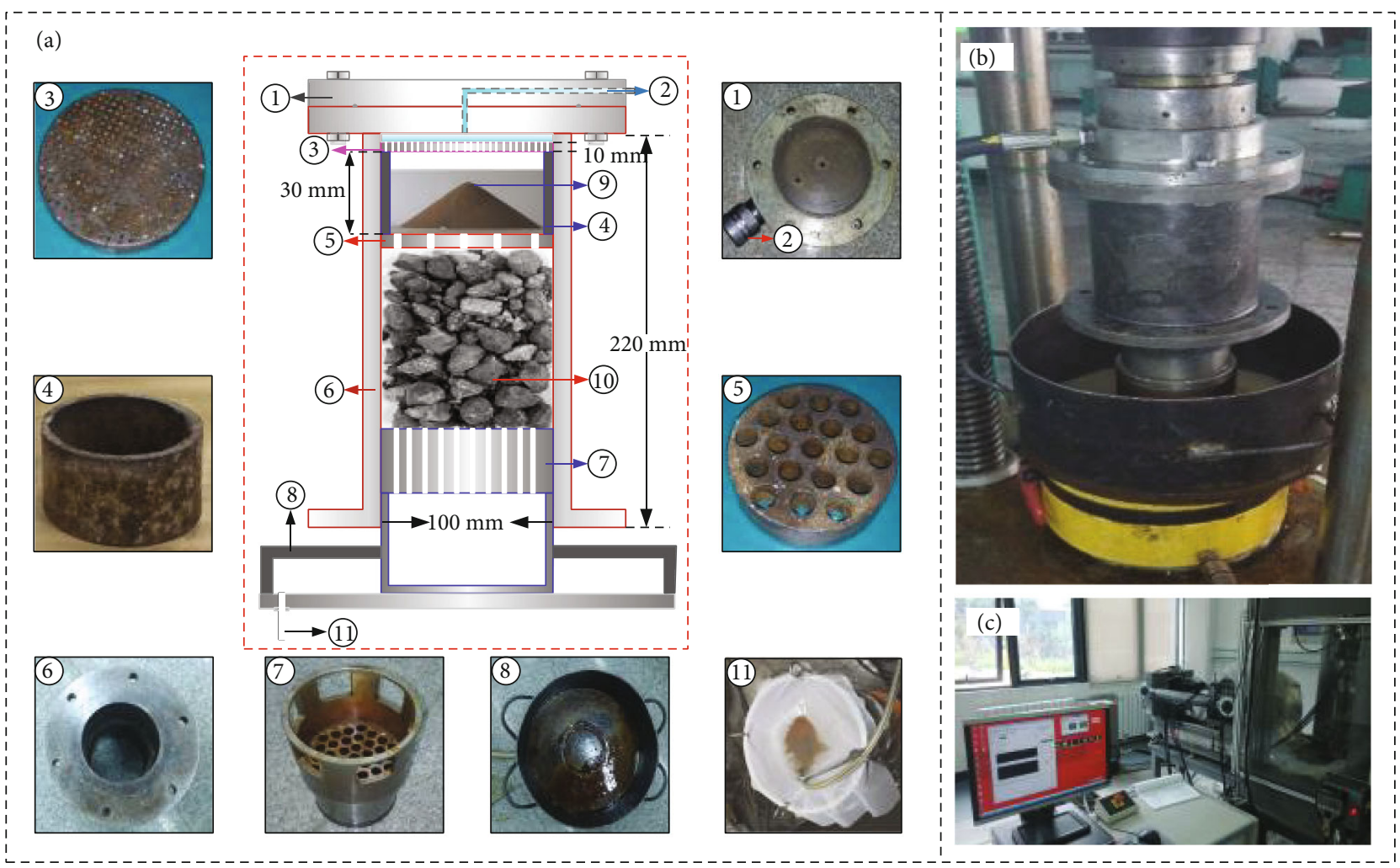

FIGURE 4: Schematic and physical diagram of the experimental system. (a) Schematic diagram and module physical diagram of the system; (b) physical penetrometer; (c) MTS816 system. Note: 1: base; 2: base inlet; 3: seepage plate; 4: pressure-bearing ring; 5: layered bulkheads; 6: main cylinder; 7: piston; 8: water and sand collection tray; 9: sand area; 10: broken rock mass; 11: water and sand outlet.

TABLE 1: The relationship between shear rate and surface viscosity.

\begin{tabular}{lcc}
\hline Size distribution & Shearing rate & Surface viscosity \\
\hline \multirow{3}{*}{$0.074-1 \mathrm{~mm}$} & 25.1327 & 0.0135 \\
& 62.8318 & 0.0065 \\
& 125.664 & 0.0032 \\
\hline
\end{tabular}
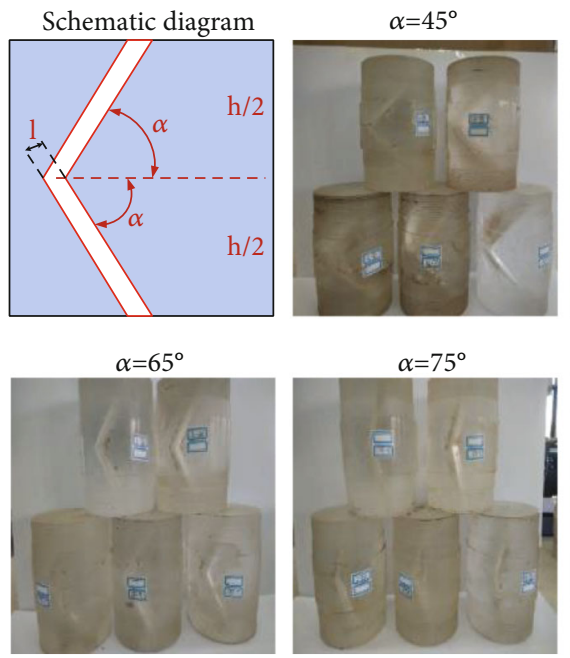

$\alpha=75^{\circ}$
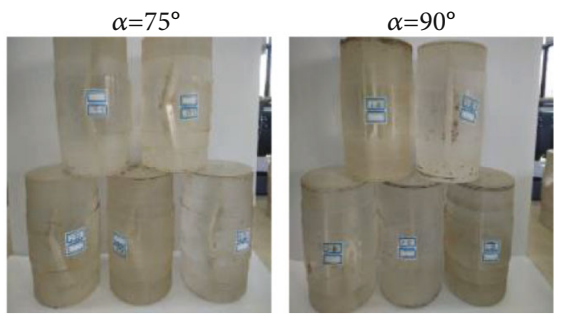

FiguRE 5: Schematic diagram and actual fracture test pieces. $l, h$, and $\alpha$ are the fracture aperture, height, and fracture angle of the sample, respectively.
Step 5. Collect the inrush sand using a filter, as well as the remaining sand in the pressure-bearing ring; subsequently, air-dry the sand and measure its mass.

\section{Experimental Results and Analysis}

3.1. Determine Porosity of the Broken Rock Mass. The size distribution of the broken rock mass is an important parameter that affects the seepage characteristics of water and sand in the broken rock mass. To avoid further fragmentation of broken rock mass under axial compression, which would obviously change the size distribution, we controlled the axial compression level within a certain range following the sample deformation law. After a certain amount of axial compression that was applied to the broken rock mass for a period of time, the deformation of the broken rock mass tended to be stable, and the final porosity and other parameters of the samples can be obtained.

The porosity $\phi$ of the broken rock mass that can be calculated by the volume of fractured rock mass in the permeameter can be obtained by the following formula:

$$
\phi=1-\frac{m}{\rho \pi r^{2} h(1-\varepsilon)},
$$

where $m$ is the quality of the broken rock mass, $\rho$ is the density of the broken rock mass $\left(2.42 \mathrm{~g} / \mathrm{cm}^{3}\right), r$ is the internal radius of the main cylinder of the permeameter, $h$ is the height of the fractured rock mass accumulated naturally, 


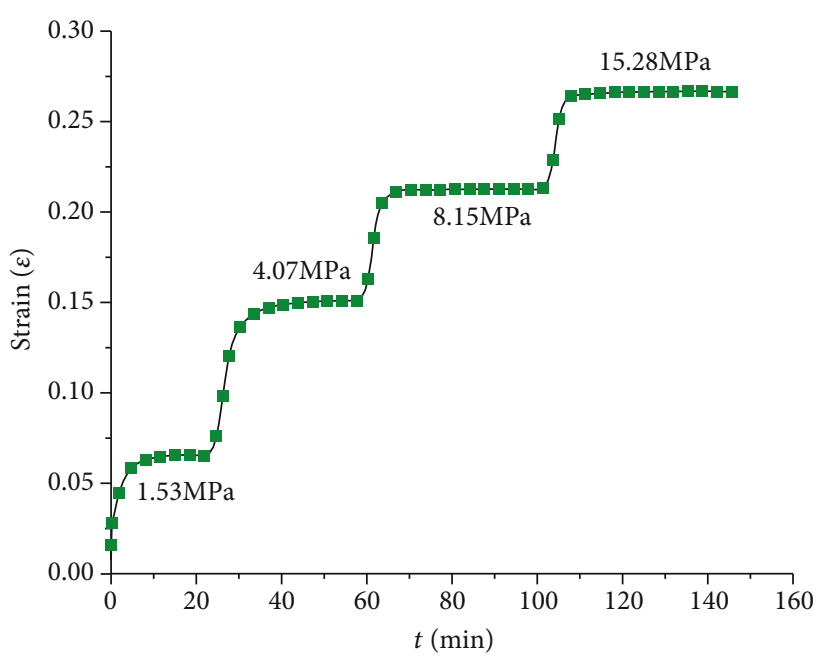

(a)

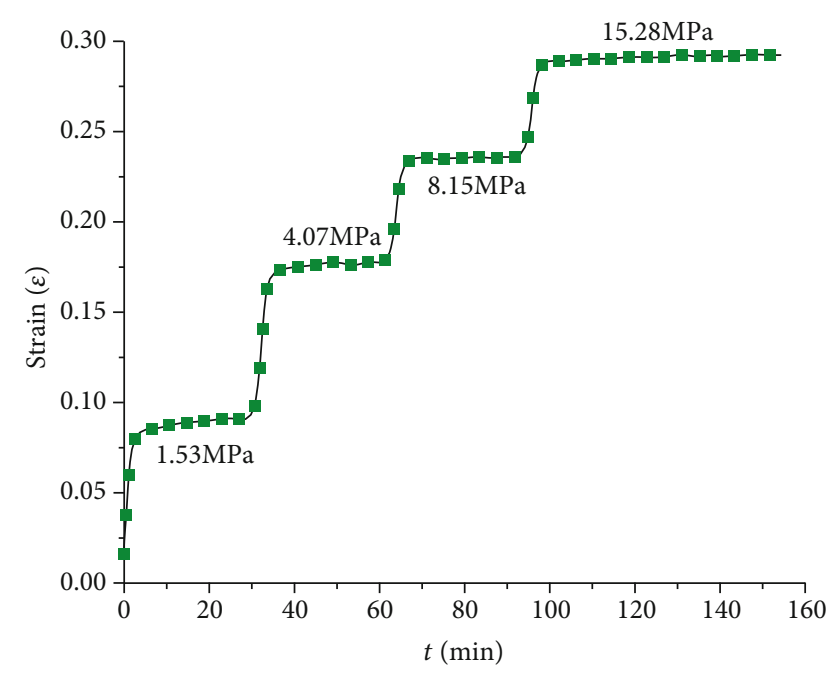

(b)

FIGURE 6: Rheological law of broken mudstone with different particle sizes: (a) 5-8 mm; (b) 12-15 mm.

TABLE 2: Relationships between porosity and axial pressure of broken rock mass with different size gradations.

\begin{tabular}{|c|c|c|c|c|c|}
\hline \multirow{2}{*}{ Axial pressure (MPa) } & \multicolumn{5}{|c|}{ Porosity $(\phi)$} \\
\hline & $5 \sim 8 \mathrm{~mm}$ & $8 \sim 10 \mathrm{~mm}$ & $10 \sim 12 \mathrm{~mm}$ & $12 \sim 15 \mathrm{~mm}$ & $15 \sim 20 \mathrm{~mm}$ \\
\hline 0.76 & 0.464 & 0.453 & 0.442 & 0.429 & 0.419 \\
\hline 1.06 & 0.444 & 0.433 & 0.421 & 0.405 & 0.393 \\
\hline 1.44 & 0.426 & 0.414 & 0.399 & 0.383 & 0.367 \\
\hline 1.94 & 0.408 & 0.395 & 0.380 & 0.362 & 0.343 \\
\hline 2.60 & 0.390 & 0.377 & 0.360 & 0.340 & 0.319 \\
\hline 3.31 & 0.375 & 0.362 & 0.344 & 0.323 & 0.299 \\
\hline
\end{tabular}

and $\varepsilon$ is the strain of the broken rock mass under axial compression.

Then, Equation (2) can be expressed as

$$
\phi=1-\frac{m}{\rho \pi r^{2} h_{t}}
$$

where $h_{t}$ is the compressed height of the broken rock mass at $t$ moment.

An axial force of $6 \mathrm{kN}, 8.3 \mathrm{kN}, 11.3 \mathrm{kN}, 15.2 \mathrm{kN}, 20.4 \mathrm{kN}$, and $26 \mathrm{kN}$ was applied to the broken rock mass, respectively, and the inner diameter of the permeameter is $100 \mathrm{~mm}$, so the corresponding axial pressure is $0.76 \mathrm{MPa}, 1.06 \mathrm{MPa}$, 1.44 MPa, 1.94 MPa, 2.60 MPa, and $3.31 \mathrm{MPa}$, respectively. Due to the different size gradations of the broken rock mass, the porosity obtained under the same axial pressure is also different. From Equation (3), the specific experimental data is shown in Table 2 and Figure 7. From that, the porosity of the samples decreases with increasing gradation, while the variability is more obvious under the loading.

3.2. Analysis of Seepage Results of the Broken Rock Mass. In the process of water and sand seepage, part of the sand would remain in the skeleton of the broken rock mass, so it would certainly change the quality and porosity of the rock mass,

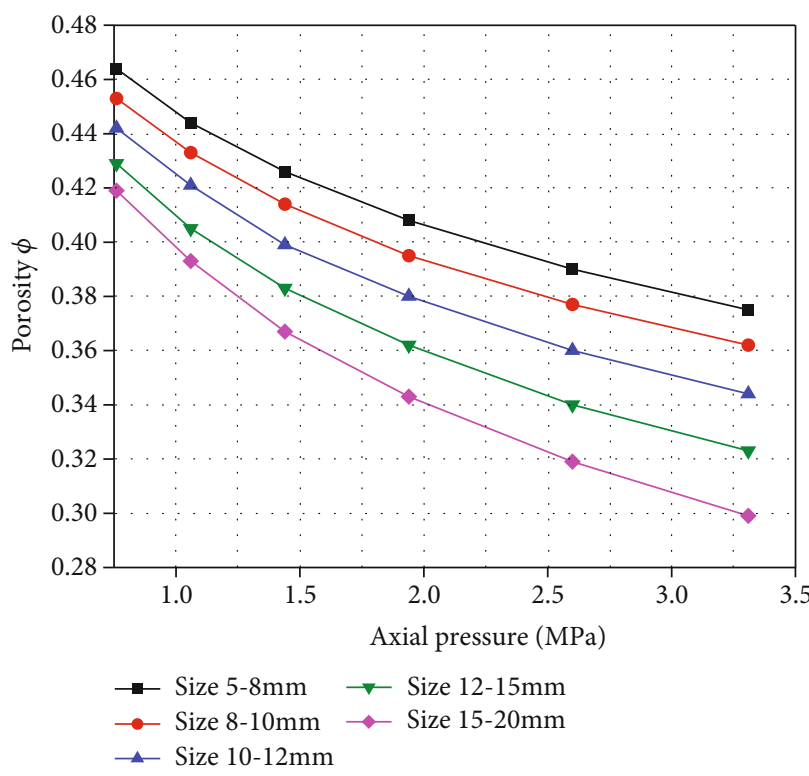

FIgURE 7: The variation of porosity with load for different broken rock samples.

while the other part of the sand would flow out of the broken rock mass with the water. The sand that flow out to the mining face will threaten the safety of the coal mining. There is 
also part of the sand that would be isolated above the broken rock mass. The entire sample in the experiment was in a closed environment, and it was difficult to observe the internal conditions dynamically. Therefore, the changes of porosity and skeleton structure of the broken rock samples would cause the changes of permeability characteristics. The focus of this paper is to analyze the characteristics of the permeability, porosity, water and sand seepage, and quality of sand inrush under different deformation processes of the broken rock mass. Assume that the seepage process conforms to Darcy's law [29], the following can be obtained.

$$
-\frac{\partial p}{\partial z}=\frac{v \mu}{k}
$$

where $k$ is the permeability and $\mu$ is the hydrodynamic viscosity.

From Equation (4), the permeability coefficient $K$ can be obtained by using

$$
K=k \frac{\gamma}{\mu}
$$

where $\gamma$ is the gravity density of the fluid.

In the process of water and sand seepage, the size gradation and the initial porosity of different broken rock mass have great influence on the motion characteristics of water and sand mixture. Figure 8 shows the quality of sand inrush when loaded with different size gradations.

The quality of the sand inrush with the initial porosity changes is shown in Figure 8. The quality of the sand inrush is a visual representation of the water and sand inrush disaster in coal mines, due to the fact that sand often submerges and damages equipment. From Figure 8, the quality of the sand inrush is obviously influenced by the structure of the fractured rock, the larger the gradation the more sand collapse quality of the sample, implying that the broken rock samples with the large gradation are more likely to form dominant sand collapse channels. Also, this indicates that the greater the hazard level of the water and sand inrush. For example, when the porosity of the broken rock sample is about 0.45 , the mass of the broken sand increases from $52.3 \mathrm{~g}$ to $118.9 \mathrm{~g}$ as the gradation of the sample changes from $10-12 \mathrm{~mm}$ to $15-20 \mathrm{~mm}$. The broken rock mass is a loose granular material, and the particles are easily moved under the action of the external forces. The particles would slide relatively until the new equilibrium state is reached. The broken rock mass with small size gradation was more likely to reach a denser structure. Contrarily, the broken rock mass with a larger size gradation was more likely to form a permeable structure, and the quality of the sand inrush was greater. Therefore, even in the case of the same initial porosity, the water and sand seepage characteristics in the broken rock mass with the different size gradations were distinct. Besides, to better describe the sand inrush situation of the broken rock mass under different size gradations, Equation (6) for the relationship between the amount of sand inrush and the initial porosity with the different size gradations was fitted, where the lower corners of $m$ which are 1, 2, 3, 4, and 5 indicate the

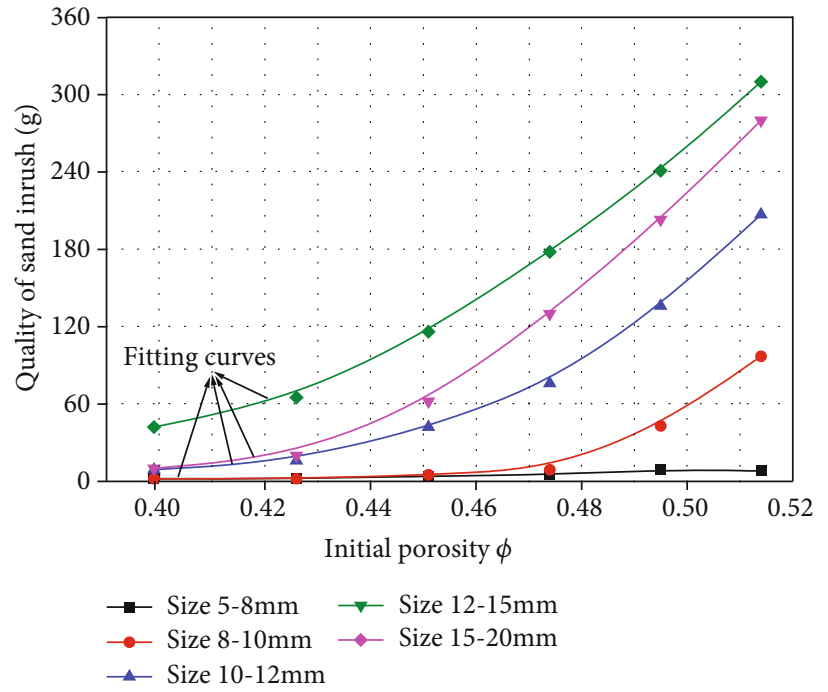

FIgURE 8: The curve of relationship between the quality of sand inrush and initial porosity of broken rock mass.

gradation of $5-8 \mathrm{~mm}, 8-10 \mathrm{~mm}, 10-12 \mathrm{~mm}, 12-15 \mathrm{~mm}$, and 15-20 $\mathrm{mm}$ of the broken rock sample, respectively.

$$
\begin{cases}m_{1}=167.42-201.19 \exp (-0.51 \phi), & R^{2}=0.898 \\ m_{2}=-1.70+1.08 \exp (45.57 \phi), & R^{2}=0.985 \\ m_{3}=-38.49+0.10 \exp (17.69 \phi), & R^{2}=0.997 \\ m_{4}=-160.72+7.16 \exp (9.63 \phi), & R^{2}=0.987 \\ m_{5}=-321.91+86.33 \exp (4.76 \phi), & R^{2}=0.996\end{cases}
$$

3.3. Effect of Fracture Shape on Water and Sand Inrush. Permeability is an important parameter that reflects the seepage characteristics of the medium. For each sample, water-sand mixture fluid was tested. The data collected by the pressure transducer was denoted by $p_{1}$, the seepage outlet was directly connected to the atmosphere, and the pressure at the outlet was denoted as $p_{0}$. The hydraulic slope was calculated as follows:

$$
J=-\frac{\partial p}{\partial x}=\frac{p_{1}-p_{0}}{h}
$$

where $J$ is the hydraulic slope along the seepage direction and $h$ is the distance at the seepage direction. The unit time flow measured by the electromagnetic flow meter was denoted by $Q$, and the flow velocity $v$ was calculated as follows:

$$
v=\frac{Q}{A},
$$

where $A$ is the sectional area of the fracture. 


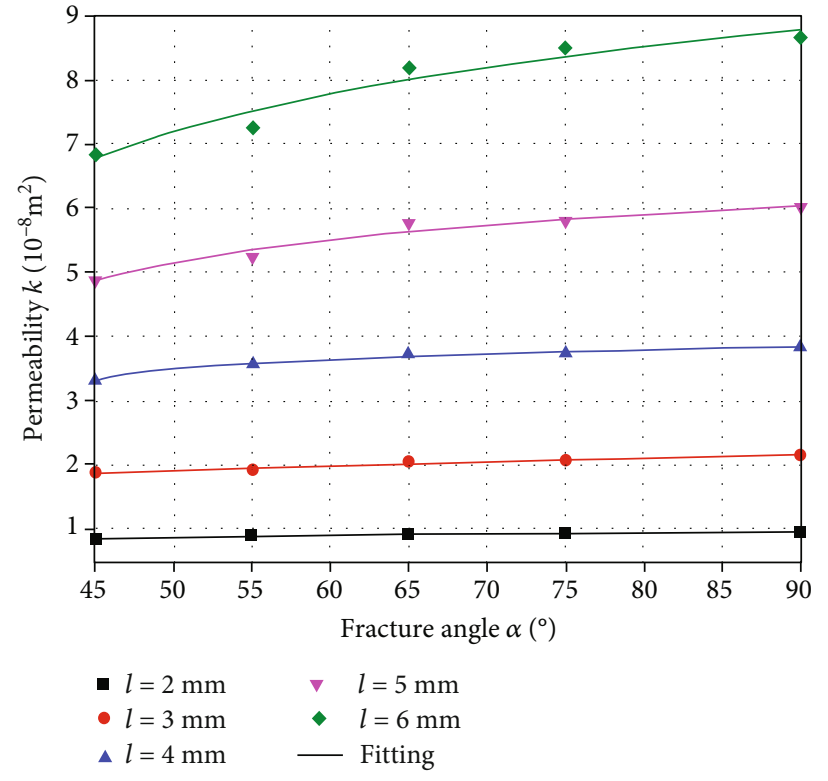

(a)

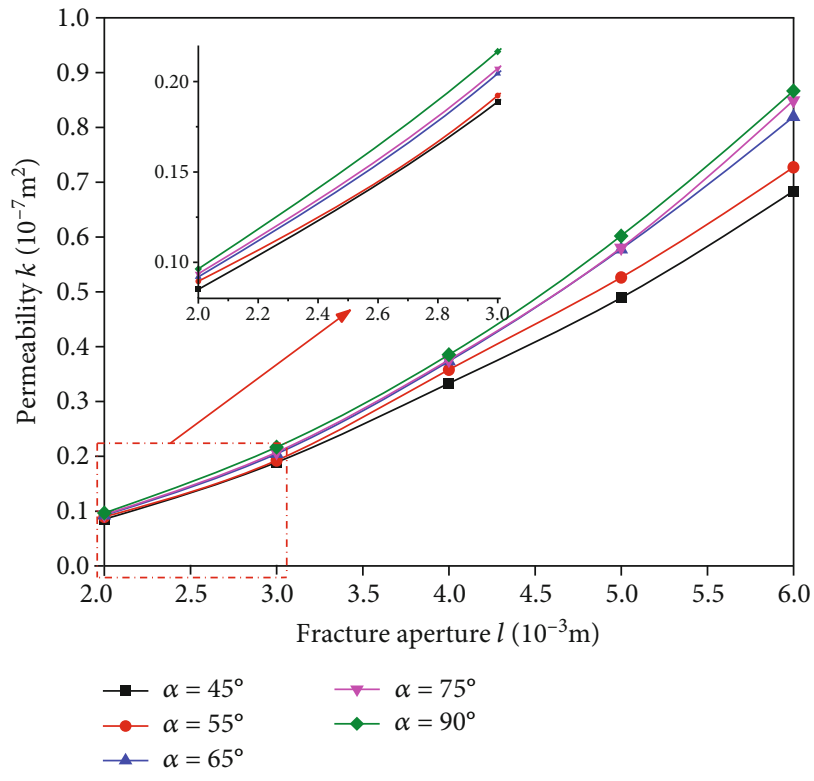

(b)

FIGURE 9: Influence of fracture angle on fracture permeability: (a) fracture angle; (b) fracture aperture.

The permeability was calculated based on Darcy's law. The power-law non-Newtonian fluid equation can be expressed by the following equation [30]:

$$
k=-\frac{v^{m} \mu}{J}
$$

where $k$ is the effective permeability.

For each fracture sample, the permeability calculated at the fluid concentration of $\mu_{i}$ was denoted by $k_{i}$, and the permeability of a sample was calculated as follows:

$$
k=\frac{1}{n} \sum_{i=1}^{n} k_{i}, \quad n=4 .
$$

Based on the pressure and flow rate data obtained in the experiments, Equations (7) and (8) were used to calculate the permeability of each fracture sample, and the permeability was influenced by its fracture aperture and angle. Figure 9 plots the influence of fracture angle on permeability in curves. As seen in Figure 9, at a fixed fracture aperture, the permeability increased at a decreasing speed along with increases of the fracture angle. When the fracture angle $\alpha$ was relatively small, the five curves were more densely distributed; as $\alpha$ increased, the five curves became farther apart. For example, when the angle of the fracture is $45^{\circ}$, the permeability $k$ increases by a factor of about 7 as the aperture increases from $2 \mathrm{~mm}$ to $6 \mathrm{~mm}$, and by the time the angle increases to $75^{\circ}, k$ increases by a factor of about 8.5. Also, it can be found that the aperture increase of the same angular sample leads to more significant variability in permeability. As the aperture increased, the curves exhibited more apparent increases, indicating greater influence of fracture angle on the permeability. In addition, the curves followed the
TABLE 3: Fitting parameters for Equation (11).

\begin{tabular}{lcccc}
\hline $\begin{array}{l}\text { Fracture aperture } \\
(l)\end{array}$ & \multicolumn{3}{c}{ Fitting coefficients } & Correlation \\
& $a / 10^{-10}$ & $b / 10^{-10}$ & $c$ & coefficient $R^{2}$ \\
\hline $2 \mathrm{~mm}$ & 81 & 3.62 & 42.2 & 0.9565 \\
$3 \mathrm{~mm}$ & 174 & 9.45 & 41.0 & 0.7895 \\
$4 \mathrm{~mm}$ & 282 & 26.63 & 38.2 & 0.9822 \\
$5 \mathrm{~mm}$ & 323 & 65.69 & 35.85 & 0.9518 \\
$6 \mathrm{~mm}$ & 342 & 136.16 & 31.55 & 0.9320 \\
\hline
\end{tabular}

characteristics of logarithm functions. Therefore, Equation (11) was used to fit the curves in Figure 9.

$$
k=b \ln (\alpha-c)+a,
$$

where $a, b$, and $c$ are fitting coefficients, as detailed in Table 3.

Furthermore, the relationship between the parameters $a$, $b$, and $c$ with the fracture aperture was fitted, and the results are shown in Equation (12). At the same time, the high determination coefficient $R^{2}$ indicates the reasonableness of the fitting results.

$$
\begin{cases}a=-7.8 \times 10^{-8} e^{-0.42 l}+4.13 \times 10^{-8}, & R^{2}=0.986, \\ b=1.09 \times 10^{-11} l^{3.98}, & R^{2}=0.974, \\ c=-2.25 e^{0.32 l}+46.7, & R^{2}=0.995 .\end{cases}
$$

It should be noted that the research in this paper is only a preliminary exploration of the water and sand inrush in broken rock mass. The results are more of a phenomenological description of the problem of sand breakout occurring in 
broken rock mass instead of a quantitative comparison of field measurement results. In addition, the indoor test results may have some deviation from the field monitoring results due to the size effect.

\section{Discussions}

When mining in a coal seam, the mining-induced fractures may pass through the overlying rock layer and then connect to the aquifer and sand layer over the coal seam [31]. Subsequently, the water-sand mixed fluid transports along the mining-induced fractures and penetrates into the broken rock mass above the mined coal, resulting in the occurrence of water and sand inrush disasters. Zhang et al. concluded that the nature of the fractures and broken rock masses has an influence on the transport of water and sand [22]. The results of this experiment also indicated that the porosity and grain size distribution of the broken rock mass have a significant effect on the quality of sand inrush. The porosity of the broken rock mass is about larger, the more sand inrush quality, which also suggested that controlling the porosity of the broken rock mass helps to reduce the impact of sand inrush hazard. In addition, the shape of the fracture is also an important factor affecting the water and sand inrush disasters [7]. As shown in Figure 9, when the water-sand mixed fluid passed through the fractures, the angle and the aperture of the fracture have a clear influence on the permeability. At a certain angle, the sample permeability increases significantly with the increase of the fracture aperture. Therefore, the prevention and control of water and sand inrush disasters can be addressed from the following aspects. (1) Reduce the aperture and angle of the fracture. For this, the mining-induced fractures should be controlled by rapid backfilling of the goaf [32]; at the same time, the surface cracks caused by the mining are backfilled quickly to close the water and sand inrush channels [4]. (2) Grouting and reinforcement: reinforcing the broken rock above the coal seam and reducing the porosity can prevent the water-sand mixed fluid from entering into the working face. (3) Reduce water flow rate. The water flow rate is an important factor in determining the possibility of water and sand inrush [33]. The water level in the aquifer can be lowered by drilling before mining to reduce the water flow rate and pressure. (4) Increase the volume fraction of sand. An increase in the volume fraction of sand increases the resistance to the flow of water-sand fluids, thereby reducing the possibility of disasters.

\section{Conclusions}

Based on the self-developed water and sand inrush experimental system, the influences of the porosity and size gradation of the broken rock mass on the water and sand seepage were analyzed. In addition, we also investigated the effects of the angle and aperture of the sample fracture on the seepage process of the water-sand mixture. The main conclusions are as follows:

(1) The changes in porosity and skeleton structure of the broken rock mass would cause the changes of the per- meability characteristics. With the increase of initial porosity, the permeability characteristics of the broken rock mass will be significantly enhanced. The broken rock mass with small size gradation was more likely to reach a denser structure. Contrarily, the broken rock mass with larger size gradation was more likely to form a permeable structure and the more easily the mixture of water and sand would break out of the broken rock mass

(2) Both fracture aperture and fracture angle had influences on the permeability of fractures. At a constant fracture aperture, the permeability increased at a decreasing speed as the fracture angle increased, which showed an exponential relationship between permeability and fracture angle. As the fracture aperture increased, the fracture angle generated greater influence on the permeability

(3) According to the experimental results, the preliminary prevention and control techniques for water and sand inrush were proposed. The main idea of these measures is to reduce the porosity, control the fissure development, reduce the flow rate, and optimize the structure of the broken rock mass. Practical engineering can control the fracture development and reduce the porosity by the grouting reinforcement technology. Meanwhile, the rapid backfilling of the surface fractures can also hinder the development of the fractures. In addition, reducing the height of the aquifer by drilling before the mining can reduce the flow rate and pressure

\section{Data Availability}

The data used to support the findings of this study are available from the corresponding author upon request.

\section{Conflicts of Interest}

The authors declare that there is no conflict of interest regarding the publication of this paper.

\section{Acknowledgments}

This work is supported by the National Natural Science Foundation of China (51974296, U1803118, 52061135111, 51904113, and 41931284).

\section{References}

[1] X. Yang, Y. J. Liu, M. Xue, T. H. Yang, and B. Yang, "Experimental investigation of water-sand mixed fluid initiation and migration in porous skeleton during water and sand inrush," Geofluids, vol. 2020, Article ID 8679861, 18 pages, 2020.

[2] G. Fan, D. Zhang, S. Zhang, and C. Zhang, "Assessment and prevention of water and sand inrush associated with coal mining under a water-filled buried gully: a case study," Mine Water and the Environment, vol. 37, no. 3, pp. 565-576, 2018.

[3] B. Chen, S. Zhang, Y. Li, and J. Li, "Experimental study on water and sand inrush of mining cracks in loose layers with 
different clay contents," Bulletin of Engineering Geology and the Environment, vol. 80, no. 1, pp. 663-678, 2021.

[4] D. Ma, H. Duan, W. Liu, X. Ma, and M. Tao, "Water-sediment two-phase flow inrush hazard in rock fractures of overburden strata during coal mining," Mine Water and the Environment, vol. 39, no. 2, pp. 308-319, 2020.

[5] Y. Xu, Y. Luo, J. Li, K. Li, and X. Cao, "Water and sand inrush during mining under thick unconsolidated layers and thin bedrock in the Zhaogu no. 1 coal mine, China," Mine Water and the Environment, vol. 37, no. 2, pp. 336-345, 2018.

[6] H. Li, J. Li, L. Li, H. Xu, and J. Wei, "Prevention of water and sand inrush during mining of extremely thick coal seams under unconsolidated Cenozoic alluvium," Bulletin of Engineering Geology and the Environment, vol. 79, no. 6, pp. 3271-3283, 2020.

[7] W. Yang, L. Jin, and X. Zhang, "Simulation test on mixed water and sand inrush disaster induced by mining under the thin bedrock," Journal of Loss Prevention in the Process Industries, vol. 57, pp. 1-6, 2019.

[8] K. Elbaz, J. S. Shen, A. Arulrajah, and S. Horpibulsuk, "Geohazards induced by anthropic activities of geoconstruction: a review of recent failure cases," Arabian Journal of Geosciences, vol. 9, no. 18, p. 708, 2016.

[9] D. Ma, H. Duan, X. Li, Z. Li, Z. Zhou, and T. Li, "Effects of seepage-induced erosion on nonlinear hydraulic properties of broken red sandstones," Tunnelling and Underground Space Technology, vol. 91, p. 102993, 2019.

[10] Z. Yu, S. Zhu, Y. Wu, and H. Yu, "Study on the structural characteristics of the overburden under thick loose layer and thinbed rock for safety of mining coal seam," Environmental Earth Sciences, vol. 79, no. 1, p. 9, 2020.

[11] G. Zhang, K. Zhang, L. Wang, and Y. Wu, "Mechanism of water inrush and quicksand movement induced by a borehole and measures for prevention and remediation," Bulletin of Engineering Geology and the Environment, vol. 74, no. 4, pp. 1395-1405, 2015.

[12] D. Ma, H. Duan, J. Liu, X. Li, and Z. Zhou, "The role of gangue on the mitigation of mining-induced hazards and environmental pollution: an experimental investigation," Science of the Total Environment, vol. 664, pp. 436-448, 2019.

[13] B. Li, R. Bao, Y. Wang, R. Liu, and C. Zhao, "Permeability evolution of two-dimensional fracture networks during shear under constant normal stiffness boundary conditions," Rock Mechanics and Rock Engineering, vol. 54, no. 1, pp. 409-428, 2021.

[14] Z. Tao, C. Zhu, M. He, and M. Karakus, "A physical modelingbased study on the control mechanisms of negative Poisson's ratio anchor cable on the stratified toppling deformation of anti-inclined slopes," International Journal of Rock Mechanics and Mining Sciences, vol. 138, p. 104632, 2021.

[15] Z. Kesseru, New Approaches and Results on the Assessment of Risks due to Undermining for Mine's Safety and for Protecting of Water Resources, International Conf on Water Resources at Risk, International Mine Water Assoc, 1995.

[16] J. Zhang and Z. Hou, "Study on sand inrush in shallow seam mining," Journal Hunan University Science and Technology, vol. 20, no. 3, pp. 15-18, 2005.

[17] A. K. Dash, R. M. Bhattacharjee, and P. S. Paul, "Lessons learnt from Indian inundation disasters: an analysis of case studies," International Journal of Disaster Risk Reduction, vol. 20, pp. 93-102, 2016.
[18] B. Zhang and Z. Lin, "A computing method for sand inrush quantity through a borehole in Longde coal mine," Advances in Civil Engineering, vol. 2018, Article ID 4842939, 11 pages, 2018.

[19] H. Pu, H. Ni, and C. Xiao, "Characteristics of water sediment two phase flows in weakly cemented fractured rock mass based on lattice Boltzmann method," Journal of China Coal Society, vol. 42, no. 1, pp. 162-168, 2017.

[20] Y. Wang, F. Geng, S. Yang, H. Jing, and B. Meng, "Numerical simulation of particle migration from crushed sandstones during groundwater inrush," Journal of Hazardous Materials, vol. 362, pp. 327-335, 2019.

[21] W. Sui, G. Cai, and Q. Dong, "Experimental research on critical percolation gradient of quicksand across overburden fissures due to coal mining near unconsolidated soil layers," Chinese Journal of Rock Mechanics and Engineering Engineering, vol. 26, no. 10, pp. 2084-2091, 2007.

[22] K. Zhang, B. Zhang, J. Liu, D. Ma, and H. Bai, "Experiment on seepage property and sand inrush criterion for granular rock mass," Geofluids, vol. 2017, Article ID 9352618, 10 pages, 2017.

[23] D. Yang, W. Guo, and Y. Tan, "Study on the evolution characteristics of two-zone failure mode of the overburden strata under shallow buried thick seam mining," Advances in Civil Engineering, vol. 2019, Article ID 9874769, 9 pages, 2019.

[24] B. Zhang, Q. He, Z. Lin, and Z. Li, "Experimental study on the flow behaviour of water-sand mixtures in fractured rock specimens," International Journal of Mining Science and Technology, 2020.

[25] Q. Yin, G. Ma, H. Jing et al., "Hydraulic properties of 3D rough-walled fractures during shearing: an experimental study," Journal of Hydrology, vol. 555, pp. 169-184, 2017.

[26] H. Huang, T. Babadagli, H. Li, K. Develi, and D. Zhou, "A visual experimental study on proppants transport in rough vertical fractures," International Journal of Rock Mechanics and Mining Sciences, vol. 134, p. 104446, 2020.

[27] Q. Yin, H. Jing, G. Ma, H. Su, and R. Liu, "Investigating the roles of included angle and loading condition on the critical hydraulic gradient of real rock fracture networks," Rock Mechanics and Rock Engineering, vol. 51, no. 10, pp. 31673177, 2018.

[28] Q. Yin, R. Liu, H. Jing, H. Su, L. Yu, and L. He, "Experimental study of nonlinear flow behaviors through fractured rock samples after high-temperature exposure," Rock Mechanics and Rock Engineering, vol. 52, no. 9, pp. 2963-2983, 2019.

[29] J. R. Chen, Y. Dong, Y. Zhang et al., "Study of characteristics of collapsing-sand considering angle and fracture opening in thin bedrocks," Yantu Lixue/Rock and Soil Mechanics, vol. 39, pp. 244-250, 2018.

[30] D. T. Snow, "Anisotropie permeability of fractured media," Water Resources Research, vol. 5, no. 6, pp. 1273-1289, 1969.

[31] D. Ma, X. Miao, H. Bai et al., "Impact of particle transfer on flow properties of crushed mudstones," Environmental Earth Sciences, vol. 75, no. 7, p. 593, 2016.

[32] J. X. Zhang, X. J. Deng, X. Zhao, F. Ju, and B. Y. Li, "Effective control and performance measurement of solid waste backfill in coal mining," International Journal of Mining, Reclamation and Environment, vol. 31, no. 2, pp. 91-104, 2017.

[33] Y. Song, "Water inrush and sand inrush mechanism and prevention technology during the initial mining period in 22402 working face of Halagou coal mine," Safety in Coal Mines, vol. 43, no. 12, pp. 91-93, 2012. 